\title{
Sistemas Silvipastoris
}

\author{
Fernando Salgado Bernardino ${ }^{(1,2)}$ e Rasmo Garcia(2) $^{(2)}$
}

(1)Bolsista Pós-Doutorado do CNPq. E-mail: fsbernardino@gmail.com; (2)Universidade Federal de Viçosa. Avenida Peter Henry Rolfs, s/n, Campus Universitário, CEP 36570-000, Viçosa-MG. E-mail: rgarcia@ufv.br

\begin{abstract}
Resumo - Apesar das pesquisas com sistemas silvipastoris terem sido iniciadas no final da década de 1970, as informações geradas até hoje não são em grande número. As vantagens advindas de um sistema silvipastoril são inúmeras e devidamente reconhecidas. Pelo fato de ser uma técnica de uso da terra capaz de recuperar ecossistemas alterados pelo mau manejo, estes sistemas, pela integração de atividades agrícolas, pecuárias e silviculturais, passam a representar uma tecnologia que confere maior sustentabilidade que os sistemas tradicionais, nos quais os monocultivos são predominantes. Nos últimos anos, instituições de ensino, pesquisa e extensão do País têm se voltado para o desenvolvimento de tais sistemas. O governo de Minas Gerais, por meio de sua Secretaria de Estado de Agricultura e de órgãos vinculados, vem promovendo a condução de modelos agrossilvipastoris num processo integrado de ocupação do solo, denominado lavoura-pecuária-silvicultura. Apesar dos grandes avanços no conhecimento de culturas anuais e dos componentes arbóreos, principalmente o eucalipto, e de gramíneas forrageiras tolerantes à diminuição da intensidade luminosa, ainda é necessário se comnhecer melhor o manejo do sub-bosque sob os efeitos do pastejo.
\end{abstract}

Termos para indexação: Eucalipto, intensidade luminosa, sub-bosque.

\section{Silvipastoral Systems}

\begin{abstract}
Although researches related to silvopastoral systems have been initiated many years ago in Brazil, there are few informations generated until now. The advantages from a silvopastoral system are inumerous and well recognized. By the fact of being a technique of land using capable of recovering several disturbed ecosystems, the silvopastoral systems by the integration of agricultural, cattle, and silvicultural activities represent a technology that can achieve higher sustainability than the traditional systems as the monocultures. Today, research centers in Brazil dedicate great attention to agrossilvopastoral systems. The government of Minas Gerais State, through the extension offices is promoting the agricultural, cattle and silvicultural practices in an integrated process of soil occupation. Even with good level of knowledge about annual crops, trees components, an example eucalyptus, and forage grasses tolerant to lower light intensity, it is necessary a better knowledge of the management of understory under the effects of grazing.
\end{abstract}

Index terms: Eucalyptus, light intensity, understory.

\section{Introdução}

Nos sistemas de produção agropecuária, a sustentabilidade pode ser considerada como a manutenção da produção ao longo do tempo, sem que ocorra a degradação dos recursos naturais dos quais a produção é dependente.

$\mathrm{Na}$ busca de alternativas para o uso múltiplo da terra, diferentes modalidades de produção se fazem necessárias, tendo em vista as consequências ecológicas das práticas inadequadas de utilização dos recursos naturais. Diante deste cenário, pode-se destacar a viabilidade técnica, ecológica e socioeconômica dos sistemas silvipastoris. Os sistemas silvipastoris (SSP), modalidade dos sistemas agroflorestais, referem-se às técnicas de produção nas quais se integram animais, plantas forrageiras e árvores, na mesma área. Tais sistemas representam uma forma de uso da terra onde atividades silviculturais e pecuárias são combinadas para gerar produção de forma complementar pela interação dos seus componentes (GARCIA; COUTO, 1997).

Estes são sistemas cuja exploração é bem mais complexa que a de pastagens exclusivas ou de florestas plantadas. A necessidade de manutenção do equilíbrio entre seus componentes (solo, árvores, forrageiras e animais), aliada ao grande número de interações possíveis entre estes e os fatores climáticos, aumenta 
a necessidade de um planejamento rigoroso, sendo determinante no sucesso da produção.

\section{Conceituação do sistema}

Quanto à sua concepção, os sistemas silvipastoris podem ser classificados em eventuais ou verdadeiros. Eventuais são aqueles em que a associação árvore/ pasto/animal se estabelece em determinado momento de uma exploração arbórea ou pecuária convencional. Neste caso, os subprodutos da exploração são manejados de modo leniente, para não prejudicar o produto principal. Já nos sistemas silvipastoris classificados como verdadeiros, o componente arbóreo, o pasto e os animais são considerados integrantes do sistema desde o planejamento do empreendimento, coexistindo na associação dentro de determinado nível de participação. São plantios regulares, feitos em espaçamentos ou densidades em que a possibilidade de supressão de um componente por outro é deliberadamente reduzida.

\section{Benefícios do sistema}

Os sistemas silvipastoris se mostram como uma promissora alternativa agroflorestal no Brasil. Segundo Carvalho e Botrel (2002), a presença do componente arbóreo na pastagem tem trazido inúmeros benefícios ao sistema, tanto para recuperação e sustentabilidade da produção de forragem, como para os aspectos de importância ecológica.

O microclima é modificado pelas árvores em um sistema silvipastoril, reduzindo a radiação solar e a relação de espectro de luz (vermelho:vermelho distante), podendo tornar a temperatura mais amena, aumentando a umidade do ar, reduzindo a taxa de evapotranspiração e aumentando a umidade do solo. Com isso, as condições ambientais no solo e na interface solo/liteira contribuem para o aumento da atividade microbiológica, tendo como consequência o aumento da taxa de mineralização dos nutrientes.

A redução na luminosidade, normalmente, diminui o crescimento das plantas, porém, no caso de sistemas silvipastoris, as mudanças que as árvores podem promover nas áreas de pastagem sob sua influência, principalmente na fertilidade do solo e nas condições microclimáticas, podem alterar as respostas esperadas (CARVALHO; BOTREL, 2002).

O processo de degradação da pastagem está, muitas vezes, relacionado à deterioração física e química do solo, componente essencial ao funcionamento de todo o sistema. Esta deterioração pode ser reduzida ou evitada com a presença do componente arbóreo, uma vez que as copas das árvores reduzem o impacto da chuva sobre o solo e a velocidade dos ventos. Além disso, o sistema radicular das árvores contribui para a sustentação do solo e melhoria das propriedades físicas, tais como porosidade, infiltração e capacidade de retenção de água. O componente arbóreo pode ser benéfico, também, por utilizar nutrientes de horizontes mais profundos do solo na produção de biomassa e devolvê-los à superfície do solo por meio da decomposição de folhas, frutos, casca, galhos, etc. (MENEZES et al., 2002). Este material, acumulado na camada superficial, além de promover a ciclagem de nutrientes, pode constituir também uma proteção adicional do solo contra erosão (PAYNE, 1985).

\section{Pesquisas em sistemas silvipastoris}

As pesquisas com sistemas silvipastoris na região Sudeste do Brasil iniciaram-se no final da década de 1970 e foram concentradas, principalmente, no Estado de Minas Gerais, onde se encontra a maioria das atividades de reflorestamento com Eucalyptus sp.

O interesse na aplicação destes sistemas vem crescendo ao longo dos anos, o que implica na maior necessidade de pesquisas envolvendo a dinâmica de crescimento, interação e de produção dos componentes arbóreo e forrageiro. No entanto, ainda são escassas as informações científicas a respeito, o que pode ser resultante da complexidade e da longa duração dos sistemas agroflorestais, aliadas ao recente início das pesquisas e ao número relativamente pequeno de técnicos trabalhando com estes sistemas em diferentes regiões do país.

Existem trabalhos que envolvem o uso de sombra artificial, na tentativa de simular o comportamento da forrageira em condição sombreada. Porém, o sistema silvipastoril vai além do sombreamento de forrageiras, pois é um ambiente com microclima próprio, envolvendo mais fatores, como fertilidade do solo, espécie arbórea, qualidade da liteira, do que apenas a modificação na transmissão de luz.

\section{Produtividade do sub-bosque}

Embora algumas plantas forrageiras que constituem o sub-bosque sejam mais tolerantes à sombra do que outras, o efeito geral de diminuição de intensidade de luz é a redução da produtividade do sub-bosque. A utilização de forrageiras tolerantes ao sombreamento é uma das condições necessárias para se obter vantagens potenciais da associação com árvores. Estas forrageiras têm que 
se desenvolver bem em condições de luminosidade reduzida e desfolha frequente, mantendo produção adequada e bom valor nutritivo. Alguns trabalhos têm avaliado a produção obtida em ambientes sombreados e em sistemas silvipastoris.

De maneira geral, as forrageiras herbáceas têm apresentado resposta variável ao sombreamento. Essas diferenças podem ocorrer devido à tolerância destas ao sombreamento; às características das árvores, como a arquitetura de copas; e fatores ambientais, como nível de sombreamento e fertilidade do solo. Na maioria dos casos em que o sombreamento tem efeito positivo sobre o crescimento das forrageiras, esse efeito esteve associado a um aumento na disponibilidade de nitrogênio $(\mathrm{N})$ no solo. O aumento dessa disponibilidade, em condições de sombreamento natural, decorre dos efeitos conjuntos de sombra e da reciclagem de nutrientes promovidos pelas árvores. Portanto, a arquitetura e características das árvores terão efeito marcante sobre a quantidade de $\mathrm{N}$ e de outros nutrientes a serem disponibilizados no solo da pastagem (CARVALHO; BOTREL, 2002).

Visando avaliar o potencial de utilização de forrageiras no Cerrado de Minas Gerais, Andrade et al. (2001) compararam o desempenho de diferentes gramíneas forrageiras (Brachiaria brizantha cv. Marandu, $B$. brizantha cv. MG-4, B. decumbens cv. Basilisk, Panicum maximum cv. Mombaça, Melinis minutiflora e Hyparrhenia rufa), consorciadas ou não com a leguminosa Stylosanthes guianensis cv. Mineirão, como constituintes do sub-bosque de sistemas silvipastoris com eucalipto. Os resultados mostraram que o desempenho da leguminosa foi insatisfatório e que a Brachiaria brizantha cv. Marandu foi, entre as gramíneas estudadas, aquela que apresentou o melhor desempenho em termos de produtividade e capacidade de cobertura do solo.

Carvalho et al. (2002) estudaram o desempenho de seis gramíneas (Brachiaria brizantha cv. Marandu, Panicum maximum cvs. Aruana, Makueni, Mombaça e Tanzânia, e Cynodon dactylon cv. Tifton 68) sob condições de luz direta e sombreadas em sistema silvipastoril com angico-vermelho (Anaderanthera macrocarpa), durante quatro períodos de avaliação. Dentre as gramíneas avaliadas, apenas o Tifton 68 foi considerado não tolerante ao sombreamento. As outras espécies e cultivares apresentaram tolerância moderada, todas experimentando redução significativa de crescimento na área sombreada, exceto no terceiro período de avaliação. O desempenho relativamente fraco dessas cultivares na área sombreada esteve relacionado, principalmente, com a baixa luminosidade incidente no verão ( $40 \%$ de transmissão de luz). Contudo, no terceiro corte, as cultivares Marandu e Mombaça chegaram a produzir, respectivamente, $30 \%$ e $14 \%$ mais matéria seca (MS) na sombra do que em pleno sol (Tabela 1). $\mathrm{O}$ fato mais interessante nesta avaliação é que o período que antecedeu o terceiro corte foi marcado por baixos índices de precipitação pluvial, mostrando que, nestas condições, o ambiente criado sob a copa das árvores pode ser mais eficiente na retenção da umidade do solo, fazendo o diferencial no crescimento das forrageiras.

Tabela 1. Porcentagem da produção de matéria seca de seis gramíneas forrageiras, em área com sombreamento por angico-vermelho comparada à área a pleno sol, em quatro épocas de avaliação.

\begin{tabular}{lcccc}
\hline & \multicolumn{4}{c}{ Época de corte (Mês) } \\
\cline { 2 - 5 } Gramínea & mar. & maio & dez. & jan. \\
\cline { 2 - 5 } & \multicolumn{4}{c}{$\begin{array}{c}\text { Crescimento na sombra em } \\
\text { relação a pleno sol (\%) }\end{array}$} \\
\hline B. brizantha cv. Marandu & 43 & 38 & 130 & 59 \\
P. maximum cv. Aruana & 17 & 35 & 86 & 43 \\
P. maximum cv. Makueni & 31 & 37 & 97 & 49 \\
P. maximum cv. Mombaça & 37 & 35 & 114 & 48 \\
P. maximum cv. Tanzânia & 38 & 35 & 93 & 69 \\
C. dactylon cv. Tifton 68 & 2 & 6 & - & - \\
\hline
\end{tabular}

Fonte: Adaptado de Carvalho et al. (2002).

Nas áreas sob as copas das árvores, o crescimento das forrageiras pode ser limitado por mudanças na qualidade de luz, ou por competição por água pelas árvores, entre outros fatores. No entanto, a competição por água pode ter pouco efeito devido à diferença de profundidade dos sistemas radiculares entre as espécies. Desta forma, as espécies arbóreas podem absorver água em maiores profundidades que os sistemas radiculares de gramíneas. Esta pode ser uma vantagem a mais dos sistemas silvipastoris, pois o componente arbóreo, ao retirar água de maiores profundidades e disponibilizá-la ao microambiente em questão, por meio de transpiração e exsudados, disponibiliza nutrientes às plantas forrageiras, cujas raízes são geralmente mais superficiais. Além disso, a biomassa que as árvores incorporam gradativamente ao sistema e volta ao solo na forma de liteira pode representar significativo aporte de nutrientes.

Visando avaliar o potencial de quatro gramíneas 
Brachiaria brizantha cv. Marandu, B. humidicola cv. Quicuio-da-amazônia, Panicum maximum cv. Massai e Paspalum notatum cv. Pensacola) e três leguminosas ( Arachis pintoi cv. Belmonte, A. pintoi BRA-031143 e Pueraria phaseoloides) para serem utilizadas em sistema silvipastoril na Amazônia, Andrade et al. (2004) utilizaram três níveis de sombreamento artificial $(0,30 \%, 50 \%$ e $70 \%)$. Os capins Marandu e Massai tiveram o melhor desempenho entre as gramíneas, aliando boa tolerância ao sombreamento e alta capacidade produtiva, constituindo opções importantes na composição de sistemas silvipastoris em áreas de solos bem drenados. O quicuio-da-amazônia apresentou menor tolerância ao sombreamento, podendo ser usado em sistemas silvipastoris com baixa densidade arbórea, em áreas com chuvas bem distribuídas ou com solos mal drenados. O capim-pensacola apresentou alta tolerância ao sombreamento, mas baixa capacidade produtiva, não sendo recomendado para a região. Dentre as leguminosas estudadas, o Arachis pintoi demonstrou maior capacidade produtiva e tolerância ao sombreamento que as demais.

\section{Qualidade do sub-bosque}

$\mathrm{Na}$ integração de forrageiras com árvores, a sombra e a biomassa do componente arbóreo têm potencial para melhorar a fertilidade do solo, aumentar a disponibilidade de nitrogênio para as forrageiras herbáceas e melhorar a qualidade da forragem (CARVALHO et al., 2001).

Castro et al. (2001), estudando o efeito de $30 \%$ e $60 \%$ de sombreamento artificial sobre as características de seis gramíneas forrageiras, constataram que o teor de fósforo $(\mathrm{P})$ foi significativamente afetado, aumentando tanto nas lâminas como nos colmos. Comportamento semelhante foi encontrado para os teores de potássio $(\mathrm{K})$, cálcio $(\mathrm{Ca})$ e magnésio $(\mathrm{Mg})$. Estes incrementos nos teores dos nutrientes eram esperados, uma vez que a produção de matéria seca neste trabalho foi reduzida com o aumento do nível de sombreamento, concentrando os nutrientes.

Carvalho et al. (2002) observaram aumento nas concentrações de $\mathrm{N}$ em diferentes gramíneas (Brachiaria brizantha cv. Marandu, Panicum maximum cvs. Aruana, Makueni, Mombaça e Tanzânia e Cynodon dactylon cv. Tifton 68) submetidas ao sombreamento natural por árvores de Anaderanthera macrocarpa, quando comparadas com o crescimento das mesmas em pleno sol. Apesar de ser sugerido um efeito de concentração desse elemento nas folhas devido à menor produção de matéria seca (MS), há relatos na literatura sobre o aumento simultâneo na produção de MS e na concentração do nutriente na planta sombreada (ERIKSEN; WHITNEY, 1981; SAMARAKOON et al., 1990). Neste trabalho, os autores verificaram que, mesmo em avaliações onde houve aumento da produção de MS, o teor de $\mathrm{N}$ também foi aumentado.

Duas considerações podem ser feitas para justificar tal aumento. A primeira é o fato de a espécie arbórea utilizada ser uma leguminosa, com potencial para fixação de $\mathrm{N}$ e possível aproveitamento do $\mathrm{N}$ fixado pela forrageira consorciada. Por outro lado, os maiores benefícios resultantes da adição regular de cobertura morta, oriunda do componente arbóreo, aos solos agroflorestais, são o aumento da dinâmica da matéria orgânica no solo e a maior disponibilidade de nutrientes para as plantas do sub-bosque.

Em estudo realizado por Andrade et al. (2002), foram avaliados os efeitos de árvores de baginha (Stryphnodendron guianense), leguminosa fixadora de $\mathrm{N}$, sobre alguns aspectos do ecossistema de pastagens. Os autores observaram que a serapilheira acumulada sob a copa das árvores, quando comparada àquela acumulada na área de pastagem aberta, apresentava melhor qualidade, com maiores teores de N, causando redução das relações $\mathrm{C} / \mathrm{N}$ e celulose/N. Já a relação lignina/ $\mathrm{N}$ foi menor na serapilheira acumulada na área aberta da pastagem, o que é justificado pela presença de material lenhoso depositado pelas árvores. O elevado teor de $\mathrm{N}$ na serapilheira sob árvores (2,18\%), juntamente com as condições microclimáticas normalmente mais favoráveis sob a copa das árvores, sugerem a existência de maior disponibilidade de $\mathrm{N}$ para as gramíneas do sub-bosque.

Ainda no mesmo trabalho, os autores observaram que as plantas crescendo sob a copa da baginha apresentaram maiores teores de proteína bruta, $\mathrm{N}$ e K, e menores teores de Ca em suas lâminas foliares, do que aquelas crescendo em pleno sol (Tabela 2). Para os teores de P e Mg não foram encontradas diferenças significativas. Conforme já comentado anteriormente, os maiores teores de $\mathrm{N}$ na forragem sombreada eram esperados. De acordo com os pesquisadores, neste trabalho, as lâminas foliares da braquiária apresentavam coloração verde-escura intensa, ao passo que na área aberta, a coloração observada foi a verde-clara, indicando deficiência de $\mathrm{N}$ no solo. Estes resultados demonstram que a presença de árvores de baginha na pastagem, além de contribuir para o aumento da disponibilidade de $\mathrm{N}$ no solo, ainda melhorou a 
qualidade da forragem crescendo sob sua copa, uma vez que o teor de proteína bruta das gramíneas sombreadas foi cerca de $50 \%$ maior que o das não sombreadas.

Tabela 2. Efeito do ambiente sobre a composição química de lâminas foliares verdes de Brachiaria spp.

\begin{tabular}{lcc}
\hline Nutriente & Sombra & Pleno Sol \\
\hline Proteína bruta (\%) & $10,83^{\mathrm{a}}$ & $7,20^{\mathrm{b}}$ \\
Nitrogênio $(\mathrm{g} / \mathrm{kg})$ & $17,33^{\mathrm{a}}$ & $11,53^{\mathrm{b}}$ \\
Fósforo $(\mathrm{g} / \mathrm{kg})$ & $1,44^{\mathrm{a}}$ & $1,44^{\mathrm{a}}$ \\
Potássio $(\mathrm{g} / \mathrm{kg})$ & $33,35^{\mathrm{a}}$ & $27,71^{\mathrm{b}}$ \\
Cálcio $(\mathrm{g} / \mathrm{kg})$ & $2,07^{\mathrm{a}}$ & $2,59^{\mathrm{b}}$ \\
Magnésio $(\mathrm{g} / \mathrm{kg})$ & $3,02^{\mathrm{a}}$ & $3,08^{\mathrm{a}}$ \\
\hline
\end{tabular}

Médias seguidas de letras distintas, na mesma linha, são diferentes $(\mathrm{P}<0,05)$ pelo teste F.

Fonte: Adaptado de Andrade et al. (2002).

\section{Fertilização}

Nas regiões tropicais, a baixa disponibilidade de nutrientes é, seguramente, um dos principais fatores que interferem na produtividade e na qualidade da forragem. Ao se utilizar um sistema silvipastoril, o fator luminosidade também pode se tornar limitante ao crescimento da forrageira, uma vez que a interceptação de luz pelo componente arbóreo neste sistema pode alcançar valores superiores a $70 \%$.

$O$ incremento na produção de matéria seca, principalmente em forrageiras com alto potencial de produção, em decorrência da aplicação de $\mathrm{N}$ e K, já foi relatado por diversos pesquisadores. No entanto, é importante conhecer como a aplicação destes nutrientes contribui para a produção e a qualidade das plantas forrageiras em sistemas silvipastoris.

Apesar de se tratar de um ecossistema mais complexo, com maior capacidade de ciclagem e realocação de nutrientes, os sistemas silvipastoris, quando manejados intensamente, necessitam de reposição de nutrientes.

Com o objetivo de verificar a existência de outros fatores, além da baixa disponibilidade de luz, interferindo no crescimento normal da gramínea, Andrade et al. (2001) conduziram um estudo em sistema silvipastoril, constituído por E. urophylla e Panicum maximum cv. Tanzânia na região dos Cerrados de Minas Gerais. Os autores concluíram que o sombreamento imposto pelo eucalipto não era o único fator interferindo no crescimento normal da gramínea. A baixa disponibilidade de nitrogênio no solo constituiu-se na principal limitação nutricional ao crescimento da gramínea. Dessa forma, observa-se que a sustentabilidade de sistemas silvipastoris verdadeiros constituídos por gramíneas e eucaliptos necessita de maiores investigações, pois é possível que o sistema não seja auto-suficiente na manutenção do $\mathrm{N}$ disponível para árvores e gramíneas.

$\mathrm{Na}$ introdução de árvores em áreas de pastagem, ou mesmo no estabelecimento de um sistema silvipastoril verdadeiro, é importante que se disponibilizem nutrientes em quantidades adequadas para atender às exigências dos componentes arbóreo e forrageiro. Uma vez crescendo juntas, as plantas podem competir por nutrientes e água, recursos limitados no sistema. A competição por nutrientes pode ser contornada com a aplicação de fertilizantes, mas é importante que no estabelecimento do sistema sejam consideradas as necessidades nutricionais de cada espécie.

Bernardino et al. (2008b) conduziram um trabalho com o objetivo de verificar a influência da adubação nitrogenada $\left(0,75\right.$ e $150 \mathrm{~kg} \cdot \mathrm{ha}^{-1}$ de $\left.\mathrm{N}\right)$ e potássica $(0$ e 100 kg.ha ${ }^{-1}$ de $\mathrm{K}_{2} \mathrm{O}$ ) no desenvolvimento de Brachiaria brizantha em um sistema silvipastoril com eucalipto. Os resultados obtidos indicaram que o crescimento da forrageira neste sistema foi restringido pela deficiência de nitrogênio. A aplicação de $\mathrm{N}$ resultou em incremento na produtividade do sub-bosque, correspondendo a um aumento de $51,9 \%$ para o tratamento contendo $150 \mathrm{~kg} \cdot \mathrm{ha}^{-1}$ de $\mathrm{N}$, sem potássio, e $66,4 \%$ para o tratamento contendo $150 \mathrm{~kg} / \mathrm{ha}$ de N, com aplicação de potássio. Por outro lado, a adubação potássica resultou em incremento da produção de MS mesmo no tratamento sem $\mathrm{N}$. Os valores de produção de MS encontrados neste experimento podem ser considerados baixos, quando comparados a dados de crescimento forrageiro em pleno sol, indicando que o crescimento da gramínea também foi influenciado pela restrição luminosa.

Em outro trabalho, Bernardino et al. (2008a) avaliaram a composição bromatológica da forragem do sub-bosque de um sistema silvipastoril com eucalipto, adubado com fertilizantes nitrogenado e potássico. Os pesquisadores verificaram que a adubação proporcionou aumento significativo nos teores de $\mathrm{N}$ e K de Brachiaria brizantha neste sistema, porém sem alterar os teores de fibra. 
Respostas fisiológicas e morfológicas do sub-bosque

De acordo com sua plasticidade fenotípica, as plantas são capazes de alterar suas características bioquímicas, fisiológicas e morfológicas em resposta a variações ambientais. A natureza dessa resposta normalmente determina a capacidade da espécie em obter sucesso ou não sob estresses ambientais temporários ou permanentes (DIAS-FILHO, 2002). O estudo dessa plasticidade fenotípica pode acrescentar muita informação no entendimento do potencial das espécies forrageiras utilizadas em sistemas silvipastoris.

Em trabalho realizado com Brachiaria brizantha e Brachiaria humidicola, em 0 e $70 \%$ de sombreamento, Dias-Filho (2002) observou que ambas as espécies foram capazes de ajustar o processo fotossintético ao sombreamento. O ponto de compensação de luz, ou seja, o nível de radiação onde a taxa fotossintética líquida é igual a zero, foi menor nas plantas sombreadas. Entretanto, a capacidade fotossintética de ambas as espécies foi reduzida quando mantidas em sombreamento permanente.

Outro tipo de resposta fisiológica que pode ocorrer em situação de baixa luminosidade é o ajuste fenotípico. Segundo Dias-Filho (2000), Brachiaria decumbens e Brachiaria humidicola desenvolvem rapidamente ajustes fenotípicos, de forma a compensar a baixa interceptação luminosa. Estes mecanismos envolvem o aumento da área foliar específica e o aumento da taxa de alongamento foliar. De acordo com os resultados obtidos pelo autor, as plantas mantidas em ambiente sombreado alocaram quantidade significativamente menor de biomassa no sistema radicular e quantidade maior nos tecidos foliares. Entretanto, esta mudança pode tornar a forrageira mais vulnerável a tipos de estresse que dependem do sistema radicular para sua recuperação, como seca, pastejo ou queima.

As principais respostas morfológicas das plantas sombreadas têm por objetivo evitar a sombra e maximizar a captação de luz pelos órgãos assimiladores (LAMBERS et al., 1998). Dentre as principais, podese destacar: aumento da relação parte aérea:raiz; alongamento de caules, pecíolos e entrenós; redução da ramificação e perfilhamento; redução no número de folhas; aumento da área foliar específica (AFE), bem como alterações na relação folha:caule e no ângulo de inclinação das folhas.

Gobbi et al. (2008) avaliaram as características morfológicas e estruturais de Brachiaria brizantha em sombreamento artificial (em pleno sol, $50 \%$ e $70 \%$ de sombreamento). Os autores observaram que, à medida que se reduziu a disponibilidade de luz, houve aumento do comprimento de lâminas foliares e colmos, resultando em maior altura média do dossel. Isto pode representar um esforço da planta para aumentar o acesso à luz disponível (PERI et al., 2007), promovendo melhor arranjo espacial das folhas e fazendo com que as plantas interceptem e utilizem a luz de forma mais eficiente. Por outro lado, os níveis crescentes de sombra promoveram diminuição da densidade populacional de perfilhos (n. $\mathrm{m}^{-2}$ ) e aumento do peso médio dos mesmos. A menor densidade populacional de perfilhos está relacionada com a menor quantidade de radiação que penetra no dossel forrageiro, uma vez que esta promove a ativação de gemas axilares e basais para formação de novos perfilhos. Além disso, sob baixa irradiância, o suprimento reduzido de fotoassimilados é alocado, preferencialmente, para os perfilhos existentes, em detrimento das gemas axilares, inibindo a produção de novos (BAHMANI et al., 2000).

Em condições de baixa irradiância, as plantas investem relativamente maior proporção de fotoassimilados no aumento da área foliar, apresentando maior área foliar específica e folhas com menor densidade de massa. Geralmente, estas alterações têm por objetivo aumentar a captação da luz incidente, aumentando a eficiência fotossintética da planta (LAMBERS et al., 1998). Este comportamento foi observado também por Gobbi et al. (2008) na avaliação de Brachiaria brizantha em condições de sombreamento.

\section{Diferimento}

O diferimento da pastagem consiste no fechamento de uma parte da área de pastagens da propriedade, antes do término do período chuvoso, com o objetivo de acumular a forragem produzida para ser consumida no período da seca. O diferimento do pasto é uma alternativa que pode ser utilizada para minimizar o efeito da estacionalidade forrageira em sistemas silvipastoris. A viabilidade da prática do diferimento depende de vários fatores como a espécie forrageira, nível de adubação nitrogenada, período de diferimento e de utilização.

Neste sentido, Fernandes et al. (2009) avaliaram a produtividade da Brachiaria brizantha cv. Marandu diferida em épocas diferentes (março, abril e maio), em combinação com adubação com N (0 e $100 \mathrm{~kg} \cdot \mathrm{ha}^{-1}$ de N), em um sistema silvipastoril com eucalipto. Os autores observaram efeito para produtividade forrageira em 
função das épocas de diferimento (Tabela 3), porém, sem influência das doses de adubo nitrogenado ou mesmo interação entre os tratamentos. Diante dos resultados encontrados, os autores recomendam que pesquisas com diferimento em áreas de sistemas silvipastoris sejam continuadas para avaliar, além da produtividade, características referentes ao valor nutritivo das plantas forrageiras.

Tabela 3. Produtividade da Brachiaria brizantha cv. Marandu em função da época de diferimento em sistema silvipastoril.

\begin{tabular}{lc}
\hline \multicolumn{1}{c}{ Época de diferimento } & Produtividade (kg/ha) \\
\hline Março & $2.082 \mathrm{a}$ \\
Abril & $1.725 \mathrm{ab}$ \\
Maio & $1.183 \mathrm{~b}$ \\
\hline
\end{tabular}

Médias seguidas da mesma letra não diferem $(\mathrm{P}>0,05)$, pelo teste de Tukey. Fonte: Fernandes et al. (2009).

\section{Produção animal}

Apesar dos recentes avanços no conhecimento sobre os sistemas silvipastoris com eucalipto, ainda existe grande carência de informações, principalmente com relação à resposta do animal e do sub-bosque ao pastejo. Aliás, avaliações de sistemas silvipastoris verdadeiros sob pastejo são escassas não apenas no Brasil, mas também na literatura mundial.

Os trabalhos avaliando o efeito do pastejo em sistemas silvipastoris, realizados até o presente momento no Brasil, tiveram pouca preocupação com a resposta do animal e do sub-bosque do sistema. A principal razão disso é que a maioria destes trabalhos foi conduzida em sistemas silvipastoris eventuais, em que os componentes animal e sub-bosque são considerados subprodutos da exploração. Como exemplo, temos os trabalhos pioneiros de Couto et al. (1988) e de Almeida (1991), que procuraram avaliar o efeito do pastejo no controle da vegetação do sub-bosque (considerada indesejável), na compactação do solo e na redução dos custos de manutenção da floresta; e o trabalho de Varella e Saibro (1997), que compararam o uso do pastejo por bovinos e ovinos com o uso de herbicidas no controle da vegetação nativa, no ano de estabelecimento, em três densidades de eucalipto.

Um dos poucos trabalhos que tiveram preocupação com a resposta dos diferentes componentes do sistema silvipastoril ao pastejo foi o realizado por Silva (1998). O autor estudou o efeito de duas densidades arbóreas (1.666 e 833 árvores de eucalipto por hectare) e de três pressões de pastejo sobre a produtividade dos componentes do sistema, sendo que o pastejo teve início aos 9 meses de idade da floresta, prolongando-se até os 25 meses. $\mathrm{O}$ autor verificou que na maior densidade arbórea houve queda muito acentuada da transmissão de luz ao sub-bosque a partir dos 10 meses de idade da floresta, diminuindo o crescimento das espécies forrageiras, e não permitindo utilização com pastejo a partir dos 18 meses de idade. Portanto, as elevadas densidades arbóreas dos sistemas silvipastoris estudados neste trabalho, que os caracteriza como eventuais, não permitiram maior aprofundamento do conhecimento sobre a relação animal $\mathrm{x}$ sub-bosque em sistemas silvipastoris verdadeiros. Diante da carência de informações sobre o desempenho de bovinos em sistemas silvipastoris verdadeiros, e também sobre a resposta do sub-bosque destes sistemas ao pastejo, aliada à crescente demanda por informações no nosso País, há a necessidade de realização de estudos com animais em pastejo nestes sistemas.

Recentemente, Bernardino et al. (2007b) avaliaram o desempenho de novilhos de corte pastejando o sub-bosque de um sistema silvipastoril composto por eucalipto e Brachiaria brizantha. Ao avaliarem o efeito da aplicação de fertilizante nitrogenado $(0$, 75 e $\left.150 \mathrm{~kg} \cdot \mathrm{ha}^{-1}\right)$ e potássico (0 e $\left.100 \mathrm{~kg} \cdot \mathrm{ha}^{-1}\right)$ em três períodos subsequentes, os autores observaram elevação dos ganhos de peso por unidade de área de animais pastejando o sub-bosque. Os ganhos foram elevados de $57 \mathrm{~kg} \cdot \mathrm{ha}^{-1}$ no tratamento sem fertilização, para $216 \mathrm{~kg} \cdot \mathrm{ha}^{-1}$ no tratamento contendo as maiores doses de fertilizante (Tabela 4). Os ganhos médios individuais foram parcialmente reduzidos, porém não comprometeram o ganho por área.

Tabela 4. Ganho de peso acumulado em três períodos (GPA) e ganho total por hectare (G/ha) de novilhos pastejando o subbosque de um sistema silvipastoril adubado com fertilizantes nitrogenado e potássico.

\begin{tabular}{|c|c|c|c|}
\hline $\begin{array}{c}\text { Dose de N } \\
\left(\mathrm{kg}^{-h^{-1}}\right)\end{array}$ & $\begin{array}{c}\text { Dose de } \mathrm{K}_{2} \mathrm{O} \\
\left(\mathrm{kg} \cdot \mathrm{ha}^{-1}\right)\end{array}$ & $\begin{array}{c}\text { GPA } \\
\left(\text { kg.animal }^{-1}\right)\end{array}$ & $\begin{array}{c}\text { G/ha } \\
\left(\mathrm{kg} \cdot \mathrm{ha}^{-1}\right)\end{array}$ \\
\hline \multirow{2}{*}{0} & 0 & 43,5 & 57,83 \\
\hline & 100 & 45,8 & 82,39 \\
\hline \multirow{2}{*}{75} & 0 & 49,5 & 132,33 \\
\hline & 100 & 55,0 & 166,78 \\
\hline \multirow{2}{*}{150} & 0 & 57,5 & 197,72 \\
\hline & 100 & 51,0 & 216,38 \\
\hline
\end{tabular}

Fonte: Bernardino et al. (2008a). 
Em outro trabalho, Bernardino et al. (2007a) avaliaram o desempenho de novilhos no sistema, sob efeito de adubação nitrogenada (0; 75 e 150 kg.ha-1) e duas ofertas de forragem ( $10 \%$ e $15 \%$ do peso vivo). Os autores concluíram que os ganhos médios individuais não foram afetados pela adubação nitrogenada ou pelos níveis de oferta de forragem, mantendo-se em níveis adequados (Tabela 5). No entanto, para intensificação do uso do sistema, com aumento do ganho de peso animal por unidade de área, a fertilização do sub-bosque se mostrou eficiente e necessária.

Tabela 5. Ganho de peso acumulado em três períodos (GPA) e ganho total por hectare (G/ha) de novilhos pastejando o subbosque de um sistema silvipastoril adubado com fertilizante nitrogenado, sob duas ofertas de forragem.

\begin{tabular}{cccc}
\hline $\begin{array}{c}\text { Doses de N } \\
\left(\mathbf{k g . h a}^{-1)}\right.\end{array}$ & $\begin{array}{c}\text { Oferta de } \\
\text { forragem } \\
(\mathbf{\%} \mathbf{P V})\end{array}$ & $\begin{array}{c}\text { GPA } \\
\left(\mathbf{k g . a n i m a l} \mathbf{~}^{-1}\right)\end{array}$ & $\begin{array}{c}\mathbf{G} / \mathbf{h a} \\
\left.\mathbf{( k g . h a}^{-1}\right)\end{array}$ \\
\hline \multirow{2}{*}{0} & 10 & 43,5 & 57,83 \\
& 15 & 44,5 & 50,83 \\
\hline \multirow{2}{*}{75} & 10 & 49,5 & 132,33 \\
& 15 & 50,0 & 144,00 \\
\hline \multirow{2}{*}{150} & 10 & 57,5 & 197,72 \\
& 15 & 52,3 & 175,50 \\
\hline
\end{tabular}

Fonte: Bernardino et al. (2008b).

\section{Leguminosas no sistema}

A utilização de leguminosas forrageiras em consórcio com gramíneas, apesar da dificuldade do manejo, é uma alternativa a ser implantada em sistemas silvipastoris. De acordo com as características fisiológicas dessas plantas, leguminosas, de ciclo $\mathrm{C} 3$, e gramíneas, de ciclo $\mathrm{C} 4$, há grande possibilidade de sucesso no consórcio, já que o nível ótimo de luz para as espécies C3 é inferior ao das C4. Com isso, espera-se redução na agressividade da gramínea, equilibrando o crescimento entre as duas forrageiras.

No entanto, em um trabalho realizado no Cerrado de Minas Gerais com sistemas silvipastoris com eucalipto, Andrade et al. (2003) não obtiveram sucesso na consorciação de Stylosanthes guianensis com Melinis minutiflora, Hyparrhenia rufa, Brachiaria brizantha cvs. MG4 e Marandu, Panicum maximum cv. Mombaça ou Brachiaria decumbens. Os autores observaram redução da proporção da leguminosa após dois ciclos de pastejo (Tabela 6), indicando que não houve redução de luminosidade suficiente para afetar o crescimento da gramínea consorciada. O capim-marandu, a $B$. decumbens e o capim-mombaça, este último especialmente, quando consorciados com o estilosantes, foram as gramíneas que apresentaram maior capacidade de produção de forragem nas condições impostas. No entanto, verificou-se que a manutenção desse consórcio é difícil, também em sistemas silvipastoris, pelo menos na fase inicial, quando o nível de sombreamento ainda é baixo. É possível que com o passar do tempo, caso a leguminosa consiga se manter no sistema, ocorra diminuição da capacidade competitiva das gramíneas, especialmente em sistemas de manejo com lotação rotacionada.

Tabela 6. Participação da leguminosa Stylosanthes guianensis cv. Mineirão no sub-bosque de um sistema silvipastoril, em função da gramínea associada.

\begin{tabular}{|c|c|c|}
\hline \multirow[t]{2}{*}{ Gramínea associada } & \multicolumn{2}{|c|}{$\begin{array}{c}\text { Participação da } \\
\text { leguminosa no sub-bosque } \\
(\%)\end{array}$} \\
\hline & $\begin{array}{c}\text { Dezembro } \\
\text { de } 1999\end{array}$ & $\begin{array}{c}\text { Abril de } \\
2000\end{array}$ \\
\hline B. brizantha $\mathrm{cv}$. Marandu & 18,3 & 2,3 \\
\hline B. decumbens & 21,7 & 6,3 \\
\hline B. brizantha $\mathrm{cv}$. MG4 & 34,0 & 13,0 \\
\hline Panicum maximum cv. Mombaça & 35,0 & 15,7 \\
\hline Hyparrhenia rufa & 40,0 & 30,0 \\
\hline Melinis minutiflora & 50,0 & 35,0 \\
\hline
\end{tabular}

Fonte: Andrade et al. (2003).

Uma opção pouco considerada para incorporar $\mathrm{N}$ ao ecossistema da pastagem é a utilização de leguminosas arbóreas fixadoras de N. Assim como o trabalho de Carvalho et al. (2002), apresentado anteriormente, encontram-se na literatura outros relatos de que a introdução de leguminosas arbóreas pode refletir em um aumento do $\mathrm{N}$ do solo e, consequentemente, em um aumento do teor de proteína bruta das forrageiras (ERIKSEN; WHITNEY, 1981; SAMARAKOON et al., 1990). Além disso, leguminosas arbóreas apresentam manejo muito mais fácil do que leguminosas herbáceas.

\section{Sequestro de carbono em sistemas agrossilvipastoris}

Os sistemas silvipastoris têm sido reconhecidos como de grande importância para a estratégia de sequestro de carbono em vários países. A utilização destes sistemas, em detrimento de pastagens exclusivas, pode promover incremento no estoque de carbono no sistema e redução dos impactos negativos decorrentes da emissão dos gases 
do efeito estufa. Sob a ótica da fixação de C, acreditase que estes sistemas possam ser mais eficientes que os tradicionais monocultivos florestais e agrícolas e as pastagens exclusivas, pelo fato de ser formado por diferentes componentes e se beneficiar das interações entre eles (TSUKAMOTO FILHO et al., 2004).

As florestas são, frequentemente, consideradas importantes drenos de carbono devido a sua capacidade de acumular grandes quantidades de matéria orgânica na biomassa lenhosa, e por proporcionar a formação de liteira mais resistente à decomposição (SHARROW; ISMAIL, 2004). A estimativa de carbono fixado pelas florestas plantadas do gênero Eucalyptus no Brasil, no período de 1990 a 1994, apresentou um aumento de 107 milhões de toneladas para 148 milhões de toneladas (BRASIL, 2002), sendo que 67,06\%, 20,68\% e 12,26\% são encontradas na parte aérea, raízes e camada orgânica do solo, respectivamente (PAIXÃO, 2004).

Por outro lado, as pastagens, apesar de também poderem ser consideradas grandes drenos de carbono, têm sido subestimadas quanto ao seu potencial para fixação do carbono atmosférico (SHARROW; ISMAIL, 2004). Isso pode ser atribuído ao fato de grande parte (até $99 \%$ ) do carbono estocado nesse ecossistema se encontrar no solo. As reservas de carbono nos solos são, geralmente, mal quantificadas nas avaliações dos ecossistemas terrestres. Tal fato tem sido decorrente das dificuldades nas medições mais representativas desse estoque de carbono, o que acaba contribuindo para a imagem negativa atribuída às pastagens.

Em estudo conduzido na região do Cerrado de Minas Gerais, por Tsukamoto Filho et al. (2004), foi quantificada a fixação de carbono em sistemas convencionais e no sistema agrossilvipastoril com eucalipto. Os autores verificaram que o sistema agrossilvipastoril fixou $2,87 \%$ mais $\mathrm{C}$ que o eucalipto em monocultivo, plantado em espaçamento de $3 \mathrm{~m}$ x $2 \mathrm{~m}$, e 133,69\%, 677,99\% e $1.177,67 \%$ mais que os monocultivos de arroz, soja e a pastagem, respectivamente. Do total fixado, grande parte do C se encontrou na fração eucalipto + liteira, conforme se pode observar na Tabela 7. No entanto, não foi realizada análise do $\mathrm{C}$ retido no solo.

Sharrow e Ismail (2004), em experimento conduzido com espécies florestais e forrageiras temperadas, relataram que as diferenças no conteúdo de $\mathrm{C}$ e $\mathrm{N}$ na biomassa têm pequena contribuição quando comparados ao estoque total do sistema. Os autores analisaram a estocagem de $\mathrm{N}$ e $\mathrm{C}$ em três sistemas: pastagem exclusiva, plantio florestal exclusivo e sistema silvipastoril. $\mathrm{O}$ solo apresentou enorme estoque de $\mathrm{C}$ nos três sistemas analisados, conforme se pode observar na Tabela 8. Na pastagem, a contribuição das frações coletadas acima do solo não chegou a $1 \%$ do $\mathrm{C}$ total. Já nos plantios florestais exclusivos, a contribuição da biomassa atingiu valores próximos a $7 \%$.

Tabela 7. Fixação de C pelo Sistema Agrossilvipastoril, em kg.ha-1.

\begin{tabular}{cccccc}
\hline $\begin{array}{c}\text { Idade } \\
\text { (anos) }\end{array}$ & Arroz & Soja & Pastagem & $\begin{array}{c}\text { Eucalipto } \\
\text { Liteira }\end{array}$ & Total \\
\hline 1 & 2.179 & - & - & 3.805 & 5.983 \\
2 & - & 1.081 & - & 15.925 & 17.005 \\
3 & - & - & 3.709 & 27.252 & 30.961 \\
4 & - & - & 3.709 & 37.170 & 40.879 \\
5 & - & - & 3.709 & 45.629 & 49.332 \\
6 & - & - & 3.709 & 52.822 & 56.531 \\
7 & - & - & 3.709 & 59.247 & 62.956 \\
8 & - & - & 3.709 & 65.211 & 68.920 \\
9 & - & - & 3.709 & 70.761 & 74.470 \\
10 & - & - & 3.709 & 75.913 & 79.622 \\
11 & - & - & 3.709 & 80.675 & 84.384 \\
\hline
\end{tabular}

Fonte: Tsukamoto Filho et al. (2004).

Tabela 8. Conteúdo médio de carbono nos vários compartimentos de uma pastagem, um sistema silvipastoril (SSP) e um plantio florestal convencional.

\begin{tabular}{lcccc}
\hline \multirow{2}{*}{ Compartimento } & \multicolumn{3}{c}{ kg.ha-1 de C $^{-1}$} \\
\cline { 3 - 5 } & & Pasto & \multicolumn{1}{c}{ SSP } & $\begin{array}{c}\text { Plantio } \\
\text { Convencional }\end{array}$ \\
\hline Árvore & 0 & $12.239 \mathrm{a}$ & $6.949 \mathrm{~b}$ \\
& Folhas & 0 & $768 \mathrm{a}$ & $486 \mathrm{~b}$ \\
& Galhos & 0 & $2.355 \mathrm{a}$ & $1.262 \mathrm{~b}$ \\
& Ramos & 0 & $1.112 \mathrm{a}$ & $694 \mathrm{~b}$ \\
& Caule & 0 & $6.490 \mathrm{a}$ & $3.660 \mathrm{~b}$ \\
& Raízes & 0 & $1.534 \mathrm{a}$ & $847 \mathrm{~b}$ \\
\hline Sub-bosque & 1.003 & 1.168 & 2.231 \\
& Forragem & $649 \mathrm{a}$ & $624 \mathrm{a}$ & $1.299 \mathrm{~b}$ \\
& Liteira & $4 \mathrm{a}$ & $95 \mathrm{a}$ & $832 \mathrm{~b}$ \\
& Esterco & $350 \mathrm{a}$ & $383 \mathrm{a}$ & $8 \mathrm{~b}$ \\
\hline Solo & & $102.520 \mathrm{a}$ & $95.886 \mathrm{ab}$ & $91.939 \mathrm{~b}$ \\
\hline Total & & $103.523 \mathrm{a}$ & $109.293 \mathrm{~b}$ & $101.119 \mathrm{a}$ \\
\hline
\end{tabular}

Médias seguidas de mesma letra não diferem entre si ao nível de 5\% de probabilidade pelo teste " $\mathrm{t}$ ".

Fonte: Sharrow e Ismail (2004). 
Os sistemas silvipastoris se mostraram mais eficientes no processo de fixação do carbono atmosférico do que os monocultivos florestais e pastagens, de forma isolada. De acordo com Sharrow e Ismail (2004), a vantagem desses sistemas pode ser atribuída à maior eficiência na captura dos recursos para crescimento, uma vez que mais componentes ativos são agregados ao processo de produção. Como a produção de biomassa nesses sistemas é representada por plantas com diferentes padrões de crescimento, é possível aumentar o estoque total de carbono na mesma área de cultivo.

O desmatamento e conversão de ecossistemas naturais para ecossistemas agrícolas diminuem drasticamente o estoque de carbono orgânico do solo. Os sistemas agroflorestais podem também exercer um efeito indireto no sequestro de carbono pelo fato de diminuir a pressão sobre as florestas naturais, as quais são as maiores armazenadoras de carbono na face da Terra. O que se pode esperar é que, nas próximas décadas, os sistemas agrossilvipastoris venham desempenhar um importante papel no mercado mundial de carbono.

\section{Considerações Finais}

Os sistemas silvipastoris representam uma tecnologia de uso da terra que garante maior biodiversidade e sustentabilidade aos ecossistemas quando comparados a quaisquer monocultivos.

O interesse pelos sistemas silvipastoris e agrossilvipastoris vem aumentando de forma significativa em todo o país. Práticas de integração da lavoura, pecuária e silvicultura já aparecem como programas de pesquisa e extensão de órgãos governamentais. Tais iniciativas são resultado do reconhecimento e necessidade de se conduzir tais sistemas em favorecimento do solo, do meio ambiente e das gerações humanas presentes e futuras.

\section{Referências}

ALMEIDA, J. C. C. Comportamento de Eucalyptus citriodora Hooker, em áreas pastejadas por bovinos e ovinos no Vale do Rio Doce, Minas Gerais. 1991. 44p. Dissertação (Mestrado em Ciência Florestal) - Universidade Federal de Viçosa.

ANDRADE, C. M. S.; GARCIA, R.; COUTO, L.; PEREIRA, O. G. Fatores limitantes ao crescimento do capim-tanzânia em um sistema agrossilvipastoril com eucalipto, na região dos cerrados de Minas Gerais. Revista Brasileira de Zootecnia, Viçosa, MG, v. 30, n.4, p.1178-1185, 2001.
ANDRADE, C. M. S. de; GARCIA, R.; COUTO, L.; PEREIRA, O. G.; SOUZA, A. L. de. Desempenho de seis gramíneas solteiras ou consorciadas com o Stylosanthes guianensis cv. Mineirão e eucalipto em sistema silvipastoril. Revista Brasileira de Zootecnia, Viçosa, v. 32, n. 6, p. 1845-1850, nov./dez. 2003.

ANDRADE, C. M. S.; VALENTIM, J. F.; CARNEIRO, J. C. Árvores de baginha (Stryphnodendron guianense (Aubl.) Benth.) em ecossistemas de pastagens cultivadas na Amazônia Ocidental. Revista Brasileira de Zootecnia, Viçosa, MG, v. 31, n. 2, sup. 2, p. 574-582, 2002.

ANDRADE, C. M. S.; VALENTIM, J. F.; CARNEIRO, J. C.; VAZ, F. A. Crescimento de gramíneas e leguminosas forrageiras tropicais sob sombreamento. Pesquisa Agropecuária Brasileira, Brasília, v. 39, n. 3, p. 263-270, 2004.

BAHMANI, I.; HARZARD, L.; VARLET-GRANCHER, C. et al. Differences in tillering of long and short-leaved Perennial Ryegrass genetic lines under full light and shade treatments. Crop Science, Madison, v. 40, n. 4 p. 1095-1102, 2000.

BERNARDINO, F.S.; TONUCCI, R.G.; GARCIA, R.; NEVES, J. C. L.; ROCHA, G. C. Composição bromatológica da forragem do sub-bosque de um sistema silvipastoril adubado com fertilizantes nitrogenado e pótássico. In: CONGRESSO NORDESTINO DE PRODUÇÃO ANIMAL, 5., 2008, Aracaju. Anais. Aracaju: Sociedade Nordestina de Produção Animal: Embrapa Tabuleiros Costeiros, 2008a. CD-ROM.

BERNARDINO, F. S.; TONUCCI, R. G.; GARCIA, R.; NEVES, J. C. L.; ROCHA, G. C. Produção de matéria seca e taxa de acúmulo de forragem em um sistema silvipastoril adubado com fertilizantes nitrogenado e pótássico. In: CONGRESSO NORDESTINO DE PRODUÇÃO ANIMAL, 5., 2008, Aracaju. Anais. Aracaju: Sociedade Nordestina de Produção Animal: Embrapa Tabuleiros Costeiros, 2008b. CD-ROM.

BERNARDINO, F. S.; GARCIA, R.; TONUCCI, R. G.; NEVES, J. C. L.; ROCHA, G. C.; GOBBI, K. F. Desempenho de novilhos de corte pastejando o sub-bosque de um sistema silvipastoril submetido a doses de fertilizante nitrogenado e duas ofertas de forragem. In: REUNIÃO ANUAL DA SOCIEDADE BRASILEIRA DE ZOOTECNIA, 44., Jaboticabal, SP. Anais... Jaboticabal: SBZ: UNESP, 2007a. 1 CD-ROM.

BERNARDINO, F. S.; GARCIA, R.; TONUCCI, R. G.; ROCHA, G. C.; GOBBI, K. F.; NEVES, J. C. L. Desempenho de novilhos de corte pastejando o sub-bosque de um sistema silvipastoril submetido a doses de fertilizante nitrogenado e potássico. In: REUNIÃO ANUAL DA SOCIEDADE BRASILEIRA DE ZOOTECNIA, 44., Jaboticabal, SP. Anais... Jaboticabal: SBZ: UNESP, 2007b. 1 CD-ROM.

BRASIL, Ministério da Ciência e Tecnologia. Emissões e remoções de dióxido de carbono por mudanças nos estoques de florestas plantadas. Brasília: MCT/FBDS, 2002. 46 p.

CARVALHO, M. M.; BOTREL, M. A. Arborização de pastagens: um caminho para a sustentabilidade de sistemas de produção animal a pasto. In: FORRAGICULTURA E PASTAGENS: TEMAS EM EVIDÊNCIA, 3., 2002, Lavras. Anais... Lavras: Editora UFLA, 2002, p. 31-76. 
CARVALHO, M. M.; FREITAS, V. P.; XAVIER, D. F. Início de florescimento, produção e valor nutritivo de gramíneas forrageiras tropicais sob condição de sombreamento natural. Pesquisa Agropecuária Brasileira, Brasília, v. 37, n. 5, p. 717-722, 2002.

CARVALHO, M. M.; XAVIER, D. F.; ALVIM, M. J. Uso de leguminosas arbóreas na recuperação e sustentabilidade de pastagens cultivadas. In:__. Sistemas agroflorestais pecuários: opções de sustentabilidade para áreas tropicais e subtropicais. Juiz de Fora: Embrapa Gado de Leite; Brasília: FAO, 2001. P. 189-204., e em Simpósio Internacional "Sistemas Agroflorestais Pecuários na America do Sul, 2000, Juiz de Fora. Anais... Juiz de Fora: Embrapa Gado de Leite; Brasília: FAO, 2000. CD-ROM.

CASTRO, C. R.; GARCIA, R.; CARVALHO, M. M. Efeitos do sombreamento na composição mineral de gramíneas forrageiras tropicais. Revista Brasileira de Zootecnia, Viçosa, MG, v.30, n.6, sup., p.1959-1968, 2001.

COUTO, L., GARCIA, R., BARROS, N. F.; GOMES, J. M. G. Redução do custo de reflorestamento no Vale do Rio Doce em Minas Gerais por meio da utilização de sistemas silvipastoris: gado bovino em eucaliptal a ser explorado. Belo Horizonte: EPAMIG, 1988. 28p (EPAMIG. Boletim Técnico, 26).

DIAS-FILHO, M. B. Growth and biomass allocation of the C4 grasses Brachiaria brizantha e B. humidicola under shade. Pesquisa Agropecuária Brasileira, Brasília, v. 35, n. 12, p. $2335-$ 2341, 2000.

DIAS-FILHO, M.B. Photosynthetic light response of the C4 grasses Brachiaria brizantha and B. humidicola under shade. Scientia Agricola, Piracicaba, v.59, n.1, p.65-68, 2002.

ERIKSEN, F.I.; WHITNEY, A.S. Effects of light intensity on growth of some tropical forage species. I: Interaction of light intensity and nitrogen fertilization on six forage grasses. Agronomy Journal, v.73, n.3, p.427-433, 1981.

FERNANDES, F.E.P.; FERNANDES, C.S.; GARCIA, R.; BERNARDINO, F.S. Produtividade da Brachiaria brizantha cv. Marandu diferida em sistema silvipastoril In: REUNIÃO ANUAL DA SOCIEDADE BRASILEIRA DE ZOOTECNIA, 46., 2009, Maringá. Anais... Maringá: SBZ, UEM. 2009. CD-ROM.

GARCIA, R.; COUTO, L. Sistemas silvipastoris: tecnologia emergente de sustentabilidade. In: SIMPÓSIO INTERNACIONAL SOBRE PRODUÇÃO ANIMAL EM PASTEJO, 1., 1997, Viçosa, MG. Anais... Viçosa, MG: UFV, 1997. p. 447-471.

GOBBI, K.F.; GARCIA, R.; GARCEZ NETO, A.F.; ROCHA, G.C.; TONUCCI, R.G.; BERNARDINO, F.S. Características morfológicas, estruturais e produtividade da Brachiaria decumbens cv. Basilisk submetida ao sombreamento. In: REUNIÃO ANUAL DA SOCIEDADE BRASILEIRA DE ZOOTECNIA, 45., 2008, Lavras. Anais... Lavras: UFLA: SBZ, 2008. 1 CD-ROM.
LAMBERS, H.; CHAPIM, F. S.; PONS, T.L. Plant physiological ecology. New York: Springer, 1998. 540p.

MENEZES, R. S. C.; SALCEDO, I. H.; ELLIOTT, E. T. Microclimate and nutrient dynamic in a silvopastoral system of semiarid northeastern Brazil. Agroforestry systems, Dordrecht, v. 56, n. 1, p. 27-38, 2002.

PAIXÃO, F. A. Quantificação do estoque de carbono e avaliação econômica de alternativas de uso de um povoamento de eucalipto. 2004. 50p. Tese (Mestrado em Ciência Florestal) Universidade Federal de Viçosa, Viçosa.

PAYNE, W. J. S. A review of the possibilities for integrating cattle and tree crop production systems in the tropics. Forest ecology and management. v. 12, n. 1., p. 1-36, 1985.

PERI, P. L.; LUCAS, R. J.; MOOT, D. J. Dry matter production, morphology and nutritive value of Dactylis glomerata growing under different light regimes. Agroforestry Systems, Dordrecht, v. 70, p. 63-79, 2007.

SAMARAKOON, S.P.; WILSON, J.R.; SHELTON, H.M. Growth, morphology and nutritive value of shaded Stenotaphrum secundatum, Axonopus compressus and Pennisetum clandestinum. Journal of Agricultural Science, v. 114, p.161-169, 1990.

SHARROW, S. H.; ISMAIL, S. Carbon and nitrogen storage in agroforests, tree plantations and pastures in West Oregon, USA. Agroforestry systems, Dordrecht, v. 60, n. 2, p. 123-130, 2004.

SILVA, J. L. S. Produtividade de componentes de um sistema silvipastoril constituído por Eucalyptus saligna Smith e pastagens cultivada e nativa no Rio Grande do Sul. 1998. 178 p. Tese (Doutorado em Zootecnia) - Universidade Federal de Viçosa.

TSUKAMOTO FILHO, A. A.; COUTO, L.; NEVES, J. C. L. Fixação de carbono em um sistema agrissilvipastoril com eucalipto na região do cerrado de Minas Gerais. Agrossilvicultura, Viçosa, MG, v.1, n.1, 2004.

VARELLA, A. C.; SAIBRO, J. C. Uso de herbicidas e de pastejo para o controle da vegetação nativa no ano do estabelecimento de três densidades de Eucalyptus saligna Smith. In: REUNIÃO ANUAL DA SOCIEDADE BRASILEIRA DE ZOOTECNIA, 34., 1997, Juiz de Fora. Anais... Juiz de Fora: SBZ, 1997. v. 2, p. 348-350.

Recebido em 22 de maio de 2009 e aprovado em 11 de dezembro de 2009 
